\title{
Protective effect of vitamin E on gastric mucosal injury in rats with biliary obstruction
}

\author{
Nuh Zafer Cantürk MD ${ }^{1}$, Zeynep Cantürk $\mathrm{MD}^{2}, \mathrm{G}_{\text {Özbilim } \mathrm{MD}^{3} \text {, C Yenisey PhD }}^{4}$
}

NZ Cantürk, Z Cantürk, G Özbilim, C Yenisey. Protective effect of vitamin $\mathrm{E}$ on gastric mucosal injury in rats with biliary obstruction. Can J Gastroenterol 2000;14(6):499-503. Patients with liver disease display increased susceptibility to gastric mucosal damage. A role of free radicals has been suggested in the development of gastric mucosal damage in normal subjects. The effects of antioxidant vitamin E treatment on the liver and stomach in cirrhotic rats were examined.

Fifty rats were divided into three groups. Cirrhosis was induced by bile duct ligation in 40 of 50 rats. Controls underwent a sham operation. Gastric mucosal lesions were produced by intragastric administration of $1 \mathrm{~mL}$ of $95 \%$ ethanol in all three groups. Twenty bile duct-ligated rats were injected intramuscularly with vitamin $\mathrm{E}$ (100 mg/kg/day). Liver and stomach histology, and stomach malondialdehyde and glutathione levels were determined. Portal hypertension was measured.

Macroscopic and microscopic gastric mucosal injury were significantly greater in the control and common bile duct-ligated groups than in the vitamin E-pretreated group $(\mathrm{P}<0.05)$. The tissue malondialdehyde and glutathione levels were significantly decreased in the vitamin E-administrated group compared with the common bile duct-ligated group $(\mathrm{P}<0.001)$. Vitamin $\mathrm{E}$ administration may be cytoprotective for both the liver and gastric mucosa in bile duct-ligated rats.

Key Words: Antioxidant; Free radicals; Obstructive jaundice; Stomach; Vitamin E

\section{Effet protecteur de la vitamine E sur les lésions de la muqueuse gastrique chez des rats atteints d'obstruction biliaire}

RÉSUMÉ : Les patients atteints d'une maladie du foie sont plus exposés à développer des lésions de la muqueuse gastrique. Le rôle de radicaux libres dans le développement de ce type de lésions chez des sujets sains a été évoqué. Les effets d'un traitement avec l'antioxidant qu'est la vitamine E sur le foie et l'estomac de rats atteints d'une cirrhose ont été étudiés.

On a divisé 50 rats en trois groupes puis, induit une cirrhose chez 40 des 50 rats par ligature du canal cholédoque. Le groupe témoin a subi une opération factice. On a provoqué des lésions de la muqueuse gastrique en administrant $1 \mathrm{~mL}$ d'éthanol à $95 \%$ par voie intragastrique aux trois groupes. Vingt rats du groupe au cholédoque ligaturé ont reçu de la vitamine $\mathrm{E}$ (100 mg/kg/jour) par voie intramusculaire. On a ensuite procédé à un examen histologique du foie et de l'estomac, mesuré les niveaux de glutathion et de malondialdéhyde de l'estomac et procédé à une mesure de l'hypertension portale.

Les lésions microscopiques et macroscopiques de la muqueuse gastrique étaient nettement plus importantes dans le groupe témoin et dans le groupe au cholédoque ligaturé que dans le groupe prétraité avec de la vitamine $E(p<0,05)$. Les niveaux tissulaires de malondialdéhyde et de glutathion étaient nettement moins élevés dans le groupe qui avait reçu de la vitamine E que dans le groupe au canal cholédoque ligaturé $(\mathrm{p}<0,001)$. L'administration de vitamine E pourrait avoir un effet cytoprotecteur à la fois sur la muqueuse gastrique et hépatique des rats au cholédoque ligaturé.
$\mathrm{P}$ atients with liver disease display increased susceptibility to gastric mucosal damage, as characterized by hemorrhagic gastropathy and peptic ulceration. In recent years, this damage has been termed 'congestive gastropathy'. It may be responsible for most of the gastrointestinal tract bleeding in patients with liver diseases (1-3).
Because of decreased acid secretion and increased hydrogen ion back diffusion, the gastric mucosa of cirrhotic patients may be sensitive to various noxious stimuli and may be protected by various agents (4-7). In addition, the congestive gastropathy causes hypoxia in the gastric mucosa and releases highly toxic free radicals (8). A previous study

${ }^{1}$ Kocaeli University, Medical School, Department of General Surgery, Kocaeli; ${ }^{2}$ Cumhuriyet University, Medical School, Department of Internal

Medicine, Sivas; ${ }^{3}$ Akdeniz University, Medical School, Department of Pathology, Antalya; ${ }^{4}$ Adnan Menderes University, Medical School,

Department of Biochemistry, Aydin, Turkey

Correspondence: Dr Nuh Zafer Cantürk, Kocaeli Universitesi Tip Fakültesi, Genel Cerrahi Anabilim Dali, Derince, Kocaili 41900, Turkey.

Telephone +90262 2292444, fax+90262 2335488, e-mail zaferc@ato.org.tr

Accepted for publication August 13, 1999 
suggested that oxygen-derived free radicals play a role in the development of acute gastric mucosal lesions induced by bile duct ligation (9). Reduced plasma levels of vitamin $E$ have been reported in patients with cirrhosis (10). Although vitamin E supplementation has been shown to be cytoprotective in several animal models of acute liver disease and in the gastric mucosa of normal rats $(10,11)$, gastric cytoprotective effects of vitamin $\mathrm{E}$ administration have not been studied in this model of liver disease. We thought that the experimental model with bile duct ligation showed spontaneous gastric mucosal damage and increased susceptibility to ethanolinduced gastric damage. Therefore, addition of antioxidants may protect the gastric mucosa against these noxious stimuli (12). We previously showed that vitamin E has cytoprotective effects on ethanol-induced hemorrhagic gastropathy in the normal and carbon tetrachloride-induced cirrhotic rat model $(11,13)$.

Our aim in the present study was to demonstrate whether supplementary vitamin $\mathrm{E}$ administration afforded gastric protective effects on ethanol-induced hemorrhagic gastritis in the bile duct ligated-rat model.

\section{ANIMALS AND METHODS}

All rats were handled in compliance with the Experimental Surgery Department of Cumhuriyet University, Turkey. The study was approved by the ethical committee of Cumhuriyet University and performed with standard guidelines for care and use of laboratory animals. Rats were kept in stainless steel cages, given food and water ad libitum, and quarantined seven days before surgery. All rats were subjected to a $12 \mathrm{~h}$ light-dark cycle. The animals were weighed just before the experiment; their mean weight was $212 \mathrm{~g}$. At the beginning of the study, rats were randomly divided into three groups: group I, control $(\mathrm{n}=10)$; group II, the common bile ductligated $(\mathrm{CBDL})$ group $(\mathrm{n}=20)$; and group III, the CBDL and vitamin E group ( $\mathrm{n}=20)$. Vitamin $\mathrm{E}$ (Roche Ltd, Basel, Switzerland) was injected intramuscularly $(100 \mathrm{mg} / \mathrm{kg} /$ day $)$ to group III throughout the study. The procedure for CBDL was as follows. Animals were anesthetized with ketamine hydrochloride and xylasine The abdomen was opened by median incision, and the common bile duct (CBD) was exposed. The CBD was ligated by two single ligatures - proximally as close as possible to the liver and distally as close as possible to the duodenum. A portion of the CBD between ligatures was cut. At the third week of CBDL, all rats in each group were fasted for $24 \mathrm{~h}$. Portal pressure was measured in each rat of each group. A PE 50 tube for each rat was inserted via a large pericolonic mesenter tributary, and pressure was measured from the level of the vena cava to the tip of a column of saline within the tubing. Gastric mucosal injury was produced by instillation of absolute alcohol via an orogastric tube. Three hours later, all animals were sacrificed; the stomachs were excised along the greater curvature and inspected for macroscopic damage, and each stomach was then cut into grips obliquely across the entire corpus. Macroscopic areas of gastric mucosal injury were assessed by an uninformed observer as follows: grade 0 , normal; grade 1 , erosions on one- third of the stomach; grade 2, erosions on two-thirds of the stomach; and grade 3, erosions on the entire stomach. The gastric mucosal lesions (erosions) were recognized using a dissecting microscope with $\times 10$ magnification. The scattered dark areas were gastric lesions that were recognized macroscopically as depressions due to breaks in the mucosa. Each stomach was cut into grips obliquely across the entire corpus, fixed in buffered formalin, and stained with hematoxylin and eosin. Specimens were evaluated by light microscopy and graded as follows: grade 0, normal; grade 0.5, polymorphonuclear cell infiltration into the lamina propria; grade 1 , mild edema, hyperemia and acute inflammation in the lamina propria; grade 2 , slight light hemorrhage, mucosal erosion, hyperemia and acute inflammation; and grade 3, diffused mucosal erosion, severe edema, hyperemia and hemorrhage. Cirrhosis of the liver was evaluated by gross inspection and by microscopic examination of liver.

Determination of tissue malondialdehyde level: Part of the removed specimens of stomach was washed with saline and stored at $-70^{\circ} \mathrm{C}$. Tissues were homogenized by cold trichloracetic acid (TCA) $(1 \mathrm{~g}$ tissue plus $1 \mathrm{~mL} 10 \%$ TCA plus $8 \mathrm{~mL} 5 \%$ TCA). Homogenates were centrifuged at $2600 \mathrm{~g}$ for 15 mins, and $1 \mathrm{~mL}$ of supernatant was mixed with $0.6 \%$ TCA. The resulting mixture was heated to $100^{\circ} \mathrm{C}$ for 10 mins and cooled for 5 mins in ice; spectrophotometric analysis was performed at $532 \mathrm{~nm}$. Data were multiplied by the molar extinction coefficient of $1.56 \times 10^{-5}(14)$.

Determination of tissue glutathione level: The homogenate $(0.5 \mathrm{~mL})$ of each sample was mixed with $1 \mathrm{~mL}$ of a solution containing $100 \mathrm{mM}$ Tris hydrochloric acid ( $\mathrm{pH} 8.2$ ), $1 \%$ sodium dodecyl sulphate and 2 mM EDTA. Fifteen milliliters of 5-aminosalicylic acid was added to each sample. The mixture was incubated for 5 mins at $25^{\circ} \mathrm{C}$ and centrifuged to remove any participant. 5,5'-Dithiobis(2-nitrobenzoate) $(45 \mathrm{~mL})$ was then added to each reaction volume and incubated for $15 \mathrm{mins}$ at $37^{\circ} \mathrm{C}$ to allow for formation of thionitrobenzoic acid (TNB). The absorbency of each sample was determined at $412 \mathrm{~nm}$. RSH content was calculated assuming a molar extinction coefficient of 13,000 at $412 \mathrm{~nm}$ for TNB (15).

Results are expressed as means \pm SE. Statistical comparisons (ordinary ANOVA and Tukey Test as post hoc test) were assumed to be significant at $\mathrm{P}<0.05$.

\section{RESULTS}

Visual evaluation of the liver indicated cholestatic changes such as congestion and edema of the liver, and dilation of the extrahepatic part of the bile duct in all rats. Histological liver changes were analyzed at the end of the experiment. Marked bile duct proliferation in expanded portal tract, extension of proliferated bile duct into the lobule, mononuclear cell infiltration into the widened portal area, vascular endothelial cell injury and some neutrophil infiltration, intracytoplasmic bile pigment accumulation in hepatocytes, bile pigment accumulation into bile canaliculus in portal area and bile pigment-phagocytosed macrophages in supportive tissue were observed in the CBDL group. There was less 


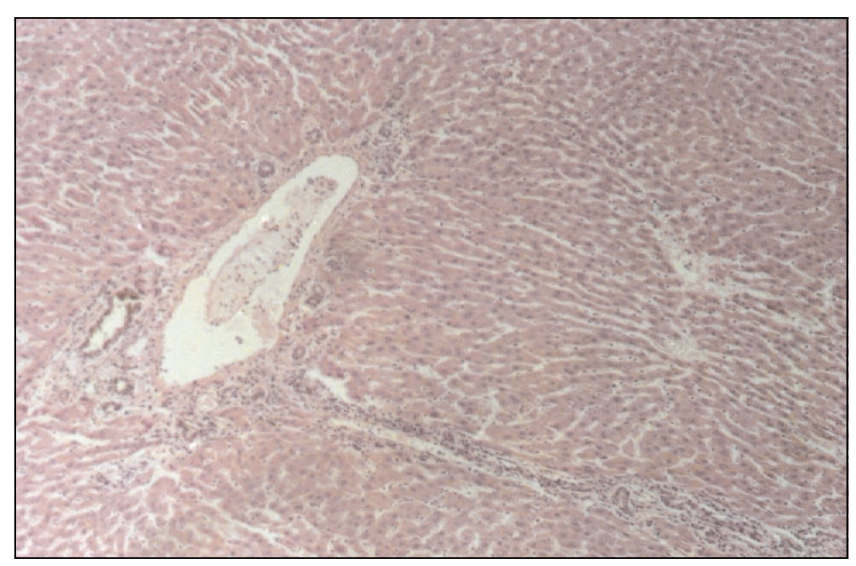

Figure 1) Histological liver samples in common bile duct-ligated (CBDL) groups. Enlarged vessels and massive inflammatory infiltration in the portal area, bile deposition in the biliary canaliculus, inflammatory cell infiltration into sinusoids and intracytoplasmic biliary pigmentation in hepatocyte (hematoxylin and eosin stain; original magnification $\times 20$ )

canalicular proliferation and mononuclear cell infiltration in the portal area, and less hepatocyte injury in the CBDL- $\alpha$ T group. (Figure 1).

Rats with ligated bile ducts had gross evidence of portal hypertension with dilated and tortuous mesenteric veins. Their portal pressure measured $26.2 \pm 3.1 \mathrm{~cm}$ saline in the CBDL group and $23.9 \pm 1.6$ in the CBDL plus vitamin E-pretreated group, compared with $17.0 \pm 2.4 \mathrm{~cm}$ saline in the control group $(\mathrm{P}<0.001)$. There were also significant differences between both CBDL groups $(\mathrm{P}<0.05)$.

Macroscopic assessment: Macroscopic areas of gastric mucosal injury after ethanol instillation were significantly larger in the control and CBDL groups than in the vitamin E-pretreated group $(\mathrm{P}<0.05)$ (Figure 2). There was no significant difference between the control group and the CBDL-vitamin E-pretreated groups ( $\mathrm{P}>0.05$ ) (Table 1).

Microscopic assessment: Microscopic studies demonstrated superficial erosions, minimal focal necrosis of the surface and foveolar cells, severe edema of the lamina propria and submucosa, erythrocyte extravasation, minimal mononuclear cell infiltration, and accompanying degenerative and regenerative changes of the surface and foveolar epithelium in all ethanol-instillated groups.

If mucosal injury after ethanol instillation was considered, superficial damage to the surface epithelial cells with their subsequent desquamation was greater in the CBDL and control groups than in the vitamin E-pretreated group $(\mathrm{P}<0.05)$ (Table 1). Although focal mucosal necrosis was superficial damage, it was more extensive in CBDL rats than in the vitamin E-pretreated and the control groups (Figures 3,4). Biochemical analysis: The results of the three groups are shown in Table 2. By the ligation and cutting of the CBD, malondialdehyde (MDA) levels increased significantly in both CBDL groups compared with the control groups $(\mathrm{P}<0.0001$ and $\mathrm{P}<0.0001$, respectively). The tissue MDA level was significantly decreased in the vitamin E-pretreated group compared with the CBDL group $(\mathrm{P}<0.001)$. Glutathione levels increased significantly in the CBDL and
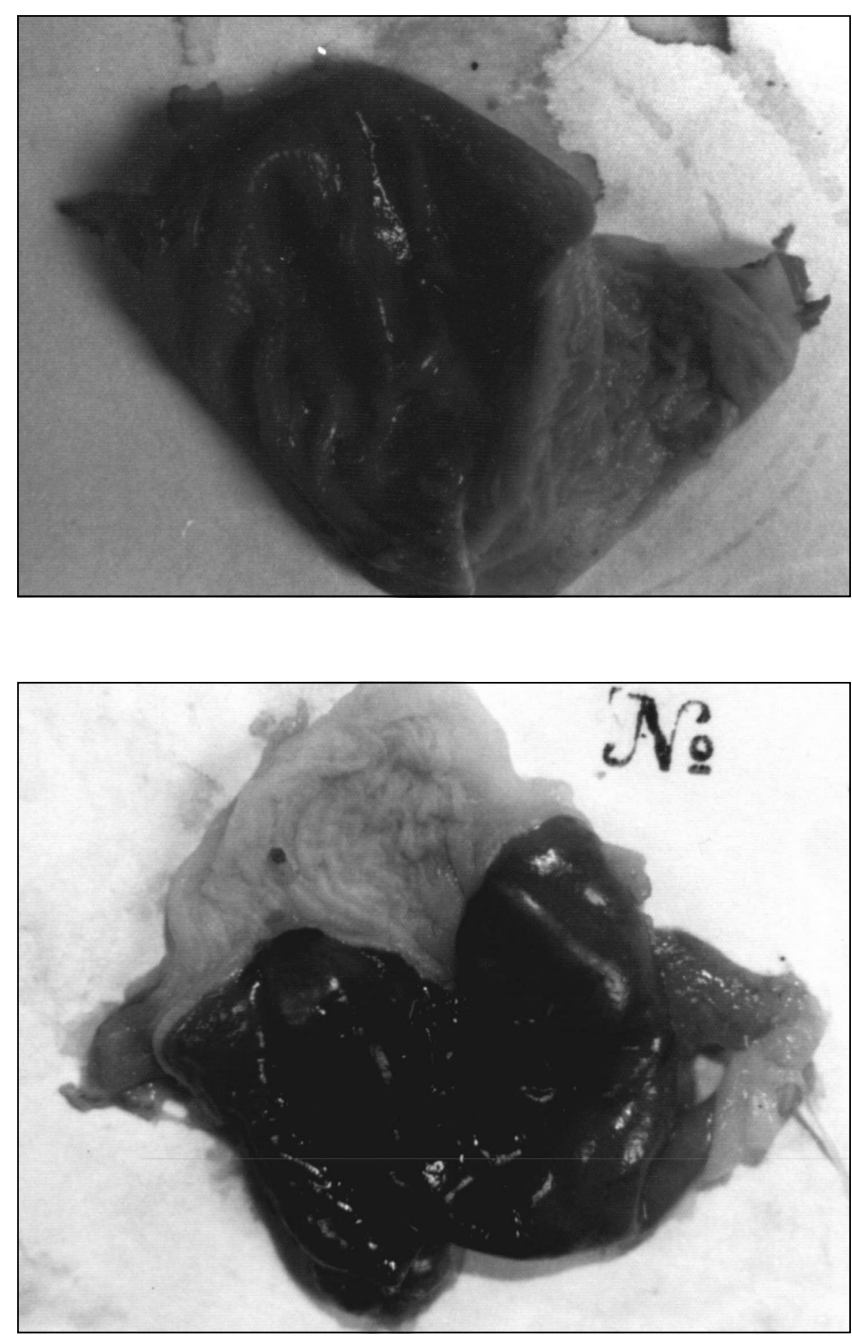

Figure 2) Gross appearance of the stomach. Top From the common bile duct-ligated group. Bottom From the Vitamin E-pretreated common bile duct-ligated group

\section{TABLE 1}

Macroscopic and microscopic scoring for gastric mucosal injury in all groups

Score for analysis of gastric mucosal injury

Macroscopic analysis Microscopic analysis

\begin{tabular}{lcc}
\hline Control group & $2.20 \pm 0.92$ & $2.23 \pm 0.95$ \\
CBDL group & $2.25 \pm 0.85$ & $2.50 \pm 0.97$ \\
CBDL-vitamin E & $1.40 \pm 1.20$ & $1.30 \pm 1.30$ \\
$\quad$ pretreated group & & \\
\hline
\end{tabular}

Macroscopic analysis: $P>0.05$, control versus $C B D L ; P>0.05$, control verusus CBDL-vitamin E-pretreated group; $P<0.05, C B D L$ versus $C B D L$ vitamin E-pretreated group. Microscopic analysis: $P>0.05$, control versus $C B D L ; P<0.05$, control verusus $C B D L$-vitamin E-pretreated group; $P<0.05, C B D L$ versus CBDL-vitamin E-pretreated group. CBDL Common bile duct-ligated

CBDL-vitamin E groups compared with the control group $(\mathrm{P}<0.0001$ and $\mathrm{P}<0.0001$, respectively). The tissue glutathione level was significantly decreased in the vitamin Epretreated group compared with the CBDL group $(\mathrm{P}<0.05)$. 


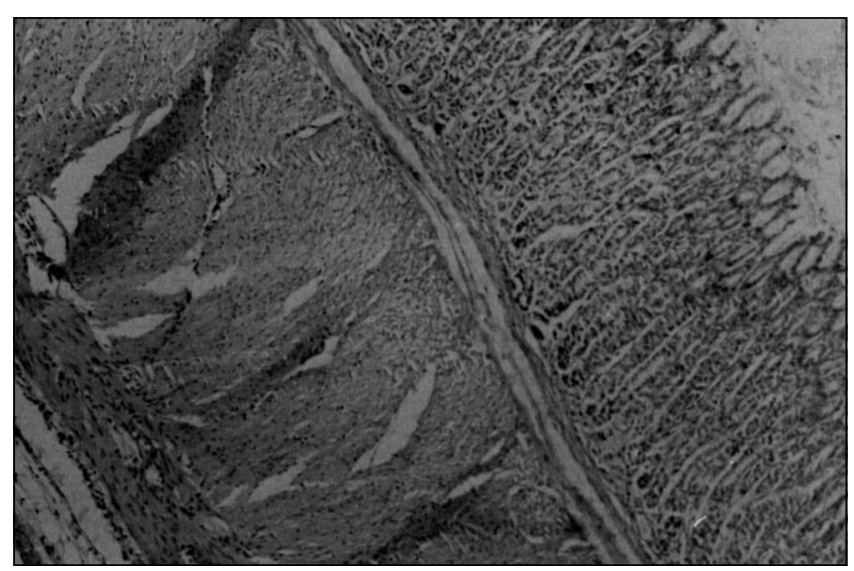

Figure 3) Microscopic appearance of the stomach with cirrhosis of the liver (hematoxylin and eosin stain; original magnification $\times 10$ )

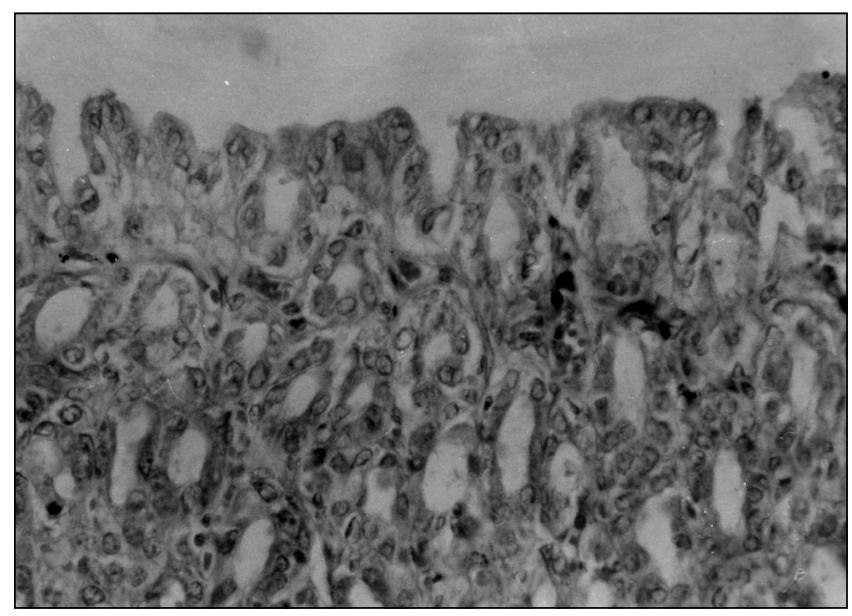

Figure 4) Microscopic appearance of the stomach with vitamin E pretreated cirrhosis of the liver (hematoxylin and eosin stain; magnification $\times 20$ )

\section{DISCUSSION}

The stomachs of patients with liver disease are frequently subject to a number of alterations, detectable by endoscopy, the presence of which indicates a disturbance in the mucosa. Less is known about factors responsible for these manifestations, although several investigators believe that changed portal flow has an etiopathogenetic role $(16,17)$. Both mild and severe gastropathy in patients with liver disease may be caused by several factors (18). As observed in the present study, histological changes of gastropathy are capillary ectasia with gastric red spot, and with or without inflammatory cellular infiltration and extravasation of red blood cells via a defective part of the endothelial cells $(17,19)$. D'Amico et al (20) reported that mild congestion of superficial capillary vessels was a common feature of mild gastropathy. These well established vascular abnormalities of gastropathy may be explained by the number of hemodynamic factors (18).

The ulcerogenic reaction to stress and chemicals involves the complex interactions between aggressive and protective mechanisms in the gastrointestinal mucosa (21). One of the major factors causing gastrointestinal injury is thought to be
TABLE 2

Stomach malondialdehyde (MDA) and glutatione GSH(x) levels for three groups

\begin{tabular}{lcc}
\hline & MDA (nmol/g) & $\mathbf{G S H}(\mathbf{x})(\mathbf{n m o l} / \mathbf{g})$ \\
\hline Control group & $11.6 \pm 2.5$ & $18.6 \pm 5.8$ \\
CBDL group & $36.6 \pm 9.3$ & $43.8 \pm 4.4$ \\
CBDL-vitamin E pretreated group & $31.7 \pm 8.3$ & $35.7 \pm 6.1$ \\
\hline
\end{tabular}

For MDA, control versus common bile duct -ligated (CBDL) group, $P<0.0001$; control versus $C B D L$-vitamin $E$ pretreated group, $P<0.0001$, $C B D L$ versus $C B D L$-vitamin $E$ pretreated group, $P<0.01$. For $G S H(x)$, control versus $C B D L, P<0.0001$; control versus $C B D L$-vitamin $E$ pretreated group, $P<0.0001, C B D L$ versus $C B D L$-vitamin $E$ pretreated group, $P<0.05$

the excessive generation of oxygen-derived free radicals, which overwhelm the endogenous antioxidant defense system $(22,23)$. Vitamin $\mathrm{E}$ is a free radical scavenger and prevents the propagation of the peroxidative process (24). Fat soluble vitamins are particularly prone to deficiency during cholestasis (25). Because vitamin E, like other fat soluble vitamins, may be poorly absorbed if any phase of fat digestion, absorption or transport is interrupted, tissue vitamin E levels decrease during chronic cholestasis (25-27); however, symptoms due to vitamin E deficiency have not been reported during the early phase of obstructive jaundice, and the effects of this deficiency are under discussion (28). In previous studies, a cytoprotective effect of vitamin E was demonstrated in a CBDL experimental rat model (29).

The results of the present investigation have demonstrated that pretreatment of bile duct-ligated rats with vitamin $\mathrm{E}$ alone markedly ameliorates gastric mucosal damage induced by absolute ethanol. A number of investigators have observed signs of vitamin E deficiency in conditions of stress $(22,30)$. Protection of the gastric mucosa by vitamin E may to some extent be attributed to its antisecretory activities. The mechanism by which vitamin $\mathrm{E}$ decreases gastric acid secretion is not clearly understood (30). Vitamin $\mathrm{E}$ has been shown to decrease calcium influx across the cell membrane (31) and to increase the level of the vasodilator prostacyclin (32). Oxygen-derived free radicals have been implicated in gastric mucosal lesions induced by various necrotizing agents (33). Vitamin E has been observed to restrict the formation of peroxides, possibly due to neutralizing free radicals $(12,33)$ and stabilizing biological membranes in general, in a manner unrelated to its antioxidant property (34). Gastric ulceration was enhanced in rats with obstructive jaundice, probably because of compromised defensive factors. Prophylaxis of acute gastric ulceration with or without obstructive jaundice may not be attained by vagotomy alone; an adequate maintenance of defensive factors seems to be also necessary (35).

Although the addition of bile acid or bilirubin to the serosal solution under experimental conditions is not the same as obstructive jaundice, studies suggest that the inhibition of bicarbonate secretion in the gastric mucosa may have an important role in the formation of acute gastric mucosal lesions 
in obstructive jaundice (36). In the present study, we examined the role of oxygen-derived free radicals in the pathogenesis of acute gastric mucosal lesions induced by obstructive jaundice in rats. As reported previously, our results suggest that oxygen-derived free radicals play a role in the development of acute gastric mucosal lesions induced by

\section{REFERENCES}

1. Triger DR, Hosking SW. The gastric mucosa in portal hypertension. J Hepatol 1989;8:267-72.

2. Sarfeh IJ, Tarnawski A. Increased susceptibility of the portal hypertensive gastric mucosa to damage. J Clin Gatroenterol 1989;13(Suppl 1):S18-21.

3. Sarin SK, Sreenivas DV, Lahoti D, et al. Factors influencing development of portal hypertensive gastropathy in patients with portal hypertension. Gastroenterology 1992;102:994-9.

4. Fraser AG, Pounder RE, Burroughs AK. Gastric secretion and peptic ulceration in cirrhosis. J Hepatol 1993;19:171-82.

5. Sarfeh IJ, Tarnawski A, Malki A, et al. Portal hypertension and gastric mucosal injury in rats: Effects of alcohol. Gastroenterology 1993;84:987-93.

6. Lebrec D, Poynard T, Hillon P. Propranolol for prevention of recurrent gastrointestinal bleeding in patients with cirrhosis. N Engl J Med 1981;305:1371-4.

7. Beck PL, McKnight GW, Kelly JK, et al. Hepatic and gastric cytoprotective effect of long term prostaglandin E1 administration in cirrhotic rats. Gastroenterology 1993;105:1483-9.

8. Kawano S, Tanýmura H, Tsuji S, et al. Impaired gastric mucosal energy metabolism in congestive gastropathy in cirrhotic patients. J Gastroenterol 1994;29:245-9.

9. Ito $\mathrm{H}$, Asahi $\mathrm{H}$, Horiuchi S. Role of oxygen radicals in the pathogenesis of acute gastric mucosal lesion under obstructive jaundice. Nippon Geka Gakkai Zasshi 1993;94:225-33.

10. de la Maza MP, Petermann M, Bunout D, et al. Effects of long-term vitamin E supplementation in alcoholic cirrhotics. J Am Coll Nutr 1995;14:192-6.

11. Utkan NZ, Cantürk NZ, Candan F, et al. [The role of oxygen free radicals and radical scavengers in ethanol induced gastric mucosal damage in rats]. Turk J Surg 1994;10:336-40.

12. Phull PS, Green CJ, Jacyna MR. A radical view of the stomach: the role of oxygen derived free radicals and antioxidants in gastroduodenal disease. Eur J Gastroenterol Hepatol 1995;7:265-74.

13. Cantürk NZ, Cantürk Z, Utkan NZ, et al. The protective effect of vitamin $\mathrm{E}$ on gastric mucosal injury in rats with cirrhosis of the liver. Chinese Med J 1998;112:56-60.

14. Pompelia A, Maellard E, Casini AF, et al. Measurement of lipid peroxidation in vivo. A comparison of different procedures. Lipids 1987;22:206-11.

15. Kurtel H, Granger DN, Tso P, et al. Vulnerability of intestinal fluid to oxidant stress. Am J Physiol 1992;263:G573-8.

16. Vigneri S, Termini R, Piraino A, et al. The stomach in liver cirrhosis. Gastroenterology 1991;101:472-8.

17. Qientero E, Pique JM, Bombi JA, et al. Gastric mucosal vascular ecstasies causing bleeding in cirrhosis. Gastroenterology 1987;93:1054-61.

18. Iwao T, Toyonaga A, Sumino M, et al. Portal hypertensive gastropathy in patients with cirrhosis. Gastroenterology 1992;102:2060-5.

19. Iwao T, Toyonaga A, Tanikawa K. Gastric red spots in patients with obstructive jaundice (9). Finally, our findings showed that vitamin $\mathrm{E}$ supplementation provided better protection to the gastric mucosa in a rat model of biliary obstructioninduced cirrhosis. Further multidose studies are necessary to determine the optimal and safe doses of vitamin $\mathrm{E}$ against congestive gastropathy.

cirrhosis: subclinical condition of gastric mucosal hemorrhage. Gastroenterol Jpn 1990;25:685-92.

20. D'Amico G, Montalbano L, Traina M, et al. Natural history of congestive gastropathy in cirrhosis. Gastroenterology 1990;99:1558-64.

21. Robert A, Szabo S. Stress ulcers. In: Selye H, ed. Selye's Guide to Stress Research. New York: Scientific and Academic Edition Publishers, 1983:22-46.

22. Tariq M. Gastric anti-ulcer and cytoprotective effect of vitamin E in rats. Res Commun Chem Pathol Pharmacol 1988;60:87-96.

23. Parks DA, Bulkley DB, Granger DN. Role of oxygen-derived free radicals in digestive tract diseases. Surgery 1983;94:415-22.

24. Infante JP. Vitamin $E$ and selenium participation in fatty acid desaturation, a proposal for an enzymatic function of these nutrients Mol Cell Biochem 1986;69:93-108.

25. Sokol RJ, Heubi JE, Iannaccone S, et al. Mechanism causing vitamin $\mathrm{E}$ deficiency during chronic childhood cholestasis. Gastroenterology 1983;85:1172-82.

26. Harries JT, Müller DPR. Absorption of vitamin E in children with biliary obstruction. Gut 1971;12:579-84.

27. Sokol RJ, Heubi JE, Simon NB, et al. Treatment of vitamin E deficiency during chronic childhood cholestasis with oral $d-\alpha$ tocopherol polyethylene glycol-1000 succinate. Gastroenterology 1987;93:975-85.

28. Müller DPR, Harries JT, Lloyd JK. The relative importance of the factors involved in the absorption of vitamin $\mathrm{E}$ in children. Gut 1974;15:966-71.

29. Cantürk NZ, CantürkZ, Utkan NZ, et al. Cytoprotective effects of alpha tocopherol against liver injury induced by extrahepatic biliary obstruction. East Afr Med J 1998;75:77-80.

30. Al-Moutairy AR, Tariq M. Effect of vitamin E and selenium on hypothermic restraint stress and chemically-induced ulcers. Dig Dis Sci 1996;41:1165-71.

31. Hall ED, Pazara KE, Braughler JM. Effects of trialazid mesylate on postischemic brain lipid peroxidation and recovery of extracellular calcium in gerbils. Stroke 1991;22:361-6.

32. Karpen CW, Merola AJ, Trewyn RW, et al. Modulation of platelet thromboxane $\mathrm{A}_{2}$ and arterial prostocyclin by dietary vitamin $\mathrm{E}$. Prostaglandins 1981;22:651-61.

33. Diplock AT. The biological function of vitamin $E$ and the nature of the interaction of vitamin with selenium. World Rev Diet 1978;31:178-83.

34. Diplock AT, Lucy JA. The biochemical mode of action of vitamin E and selenium: a hypothesis. FEBS Lett 1973;29:205-9.

35. Miyakawa H, Kameyama J, Sasaki I, et al. Experimental study on acute gastric ulceration in rat - including influence of obstructive jaundice and vagotomy. Nippon Geka Gakkai Zasshi 1983;84:113-8.

36. Kameyama J, Suzuki A, Tsukamoto M, et al. Effects of bile acids and bilirubin on bicarbonate secretion of isolated guinea pig antrum. J Clin Gastroenterol 1992;14(Suppl 1):S102-6. 


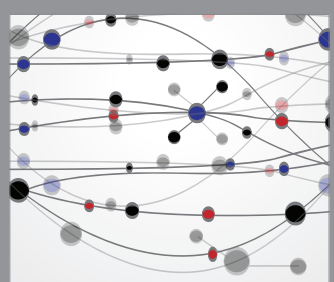

The Scientific World Journal
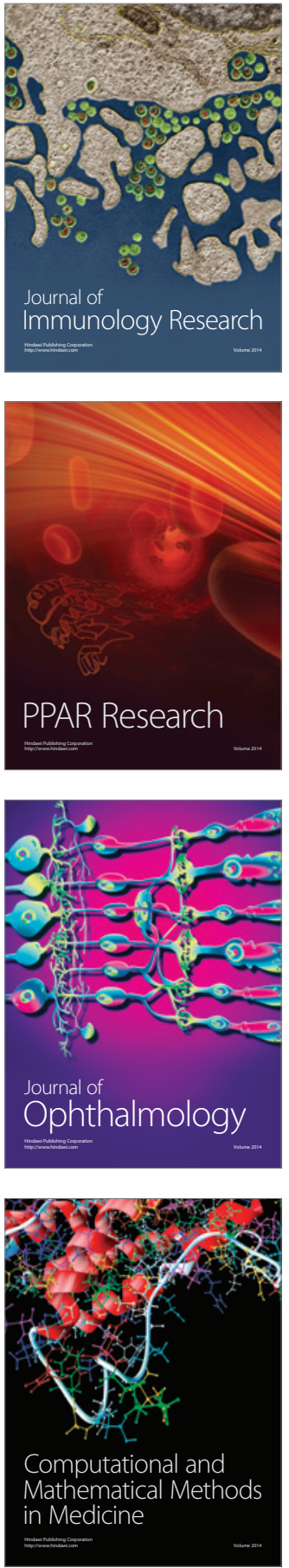

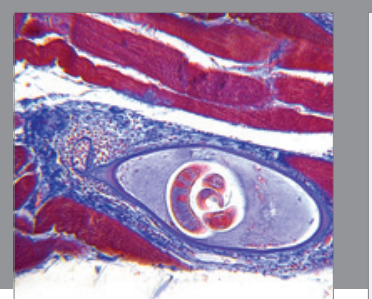

Gastroenterology Research and Practice

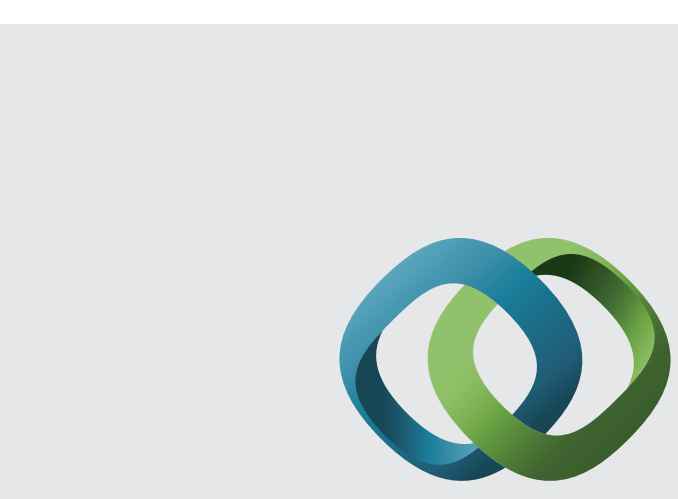

\section{Hindawi}

Submit your manuscripts at

http://www.hindawi.com
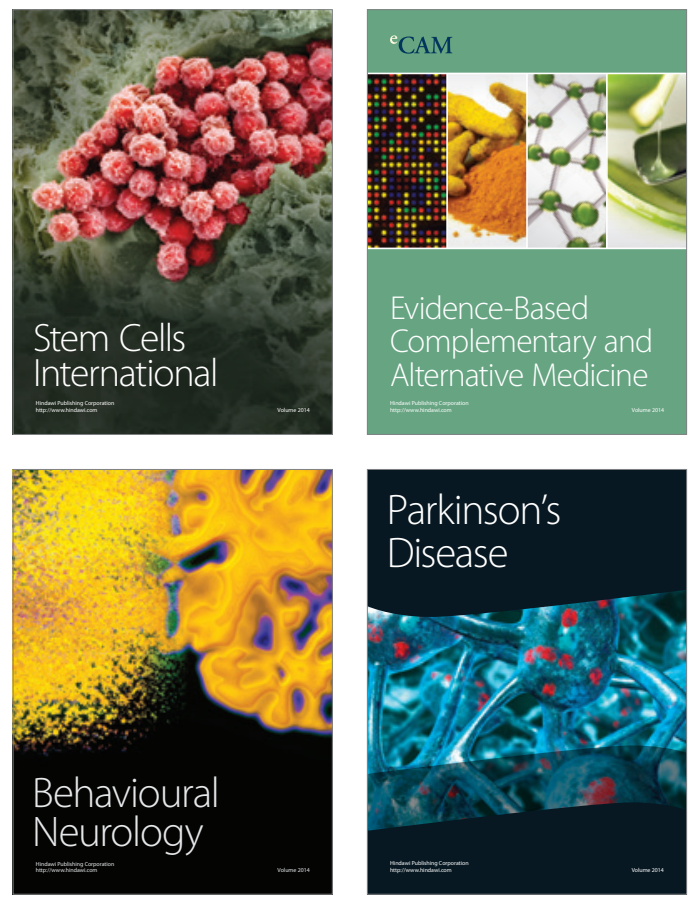
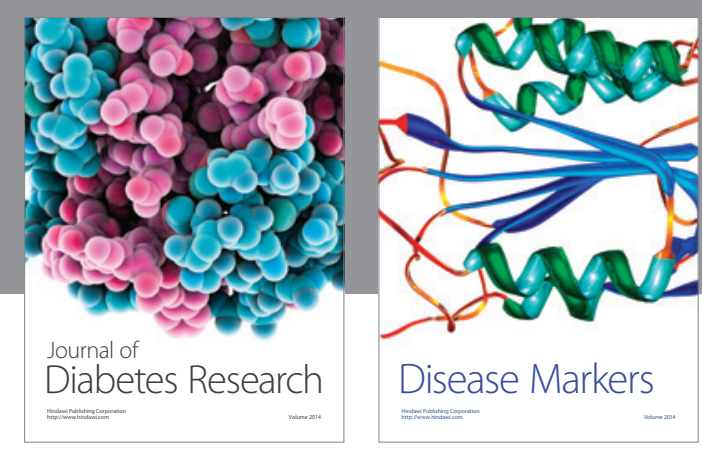

Disease Markers
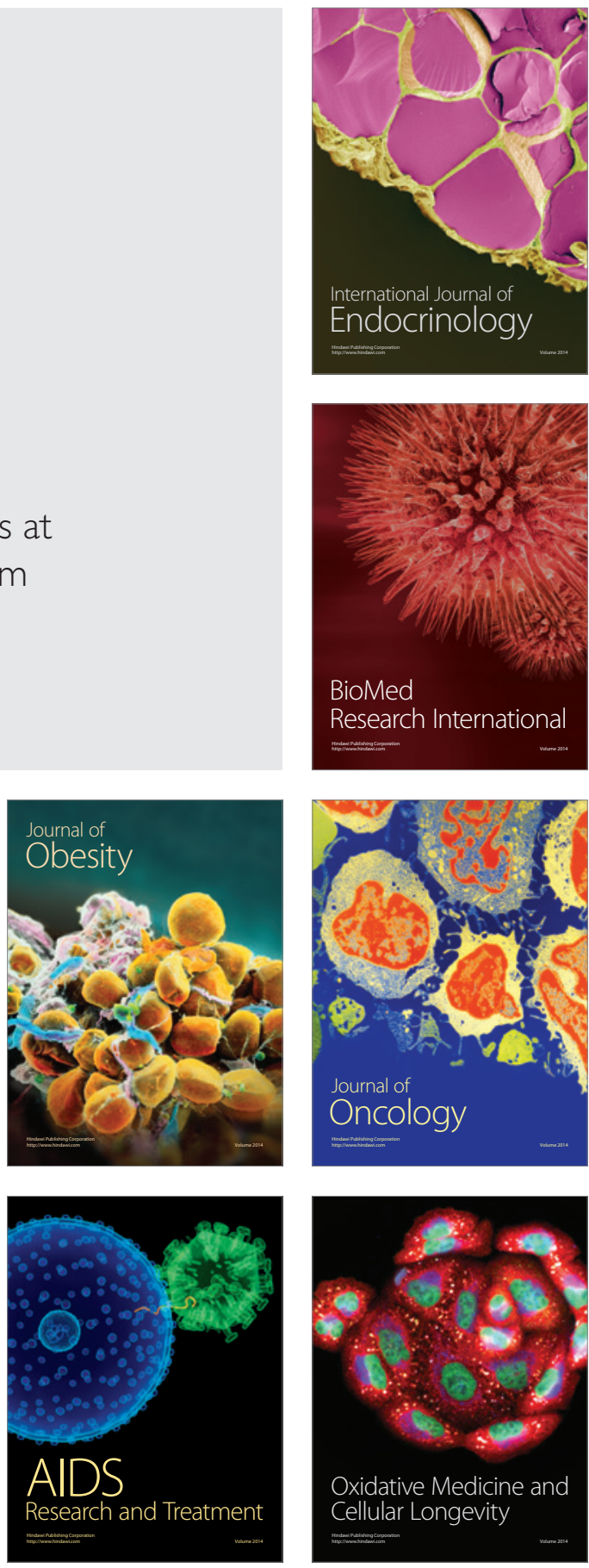